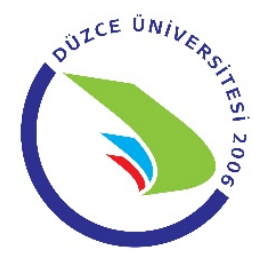

\title{
Aile İçi Şiddete Uğrayan Bir Kadının Değişim Modeli’ne Göre İncelenmesi: Olgu Sunumu
}

\author{
Sevil ÇIÇEK ${ }^{1}{ }^{1}$, Şengül YAMAN SÖZBİR ${ }^{1}{ }^{1}$, Ayten ŞENTÜRK ERENEL ${ }^{1}$
}

\section{ÖZ}

Aile içi şiddet, günümüzde devam eden evrensel bir sorundur. Çalışmada sunulan olgu S., 33 yaşında, üniversite mezunu bir ev hanımıdır. S. yaklaşık dört yıldır eşi tarafından aile içi şiddete maruz kalmaktadır. S.'nin güçlendirilmesi ile şiddete "dur" diyebilmesi amacıyla Değişim Modeli uygulanmıştır. S. ile toplam 6 görüşme yapılmıştır. S.'nin evinde yapılan her bir görüşme, yaklaşık 1 saat sürmüştür. İlk dört görüş̧e bir hafta aralıklarla yapılmıştır. Beşinci görüşme, dördüncü görüşmeden bir ay sonra ve son görüşme ise beşinci görüşmeden altı ay sonra yapılmıştır. Uygulama toplam 10 ay sürmüştür. Yapılan ilk görüşmede S.'nin niyet aşamasında olduğu saptanmıştır. Değişim aşamalarına yönelik uygulanan değişim süreçleri (bilişsel ve davranışsal süreçler) sonrasında yapılan dördüncü görüşmeden sonra S., hazırlık aşamasına ve beşinci görüş̧mede ise eylem aşamasına geçmiştir. Son görüşmede ise S.’nin sürdürme aşamasında olduğu saptanmıştır. Aile içi şiddete uğrayan kadınlarda Değişim Modeli'nin kullanılmasının, kadının güçlendirilerek şiddeti durdurmasında uygun süreçlerin planlanması, müdahalelerin uygulanması ve değerlendirmesinde etkili olacağı düşünülmektedir.

Anahtar Kelimeler: Aile içi şiddet; modeller; hemşirelik; olgu sunumları.

\section{Investigation of the Transtheoretical Model a Woman Who Exposed to Domestic Violence: A Case Report}

\section{ABSTRACT}

Domestic violence against women is an ongoing universal question. The case presented in the study is a 33-year-old housewife with a university degree. S. has been exposed to domestic violence by his wife for almost four years. With the empowerment of S., the Transtheoretical Model was applied in order to be able to say "stop". A total of 6 interviews were conducted with S. Each interview lasted about an hour. The first four interviews were performed at intervals of one week. The fifth interview was held one month after the fourth interview and the last one was six months after the fifth interview. The application lasted for 10 months. In the first interview, it was determined that $\mathrm{S}$. was at the intention stage. After the fourth meeting after the change processes applied to the change stages, S. went to the preparation stage and in the fifth interview to the action stage. In the last meeting, it was determined that $S$. was in the maintenance phase. It is thought that the use of the Transtheoretical Model in women who are subjected to domestic violence will be effective in planning and implementing appropriate interventions and evaluating women's empowerment in stopping violence.

Keywords: Domestic violence; models; nursing; case reports.

\section{GíRIŞ}

Aile içi şiddet, kendini aile olarak tanımlamış bir topluluk içerisinde, bir birey ya da gruba karşı yaralanma ya da ölümle sonuçlanma olasıllğı yüksek her türlü şiddet davranışıdır (1). Aile içi şiddet tanılanması ve müdahalesi zor bir sorundur. Aile içi şiddetin çözümüne yönelik birçok disiplin çalışmakta, pek çok ulusal ve uluslararası düzenlemeler yapılmaktadır (2). En yaygın görülen aile içi şiddet türü erkeğin kadına yönelttiği şiddettir. Aile içi şiddete maruz kalan (özellikle fiziksel) kadınlarla, en çok karşılaşma ihtimali bulunan yerler sağlık kuruluşlarıdır. Bu nedenle sağlık 
personeli, aile içi şiddete uğrayan kadınlara yönelik bakım ve destek sağlamada, şiddeti azaltmada ve iyileştirilmiş sonuçlara katkıda bulunmada önemli bir konumdadır. Sağlık personelleri içinde de hemşireler karşılaştıkları vakalarda; bireyi fiziksel, sosyal, psikolojik olarak ilk değerlendiren, birey ve ailesi ile ilk iletişime geçen meslek üyeleridir (3). Bu nedenle aile içi şiddeti belirlemede, tanılamada ve ele almada hemşireler, büyük sorumluluklara sahiptir. Ancak, şiddete maruz kalan kadınların tanılanması ve müdahalesini etkileyen birçok engel vardır. $\mathrm{Bu}$ engeller arasında; şiddeti tanılama ve müdahaleye yönelik bilgisizlik-nasıl yaklaşacağını bilememe, korku-kendi güvenliğinden endişe duyma, uygun koşulların (zaman, ortam, vb.) olmayışı ve aile içi şiddetin çözümsüz ya da sosyal bir sorun olduğu düşüncesi yer almaktadır $(3,4)$. Ayrıca aile içi şiddete maruz kalan kadınlar genellikle duygusal bağımlılık, mali kısıtlılıklar, korku, kendi kendini suçlu hissetme ve tek başına yaşayamayacağına ilişkin kaygılar nedeniyle şiddete "dur" diyememektedirler (5).

Günümüzde şiddetin tanılanması ve ele alınmasında sağlık personelinin kullanabileceği çeşitli eğitim programları ve modeller bulunmaktadır. Bu modellerden biri Transteorik Model (Değişim Modeli)'dir (6). Değişim Modeli ile şiddete uğrayan kadının güçlendirilmesi ve baş etmelerinin artırılması ile şiddete "dur" diyebilmesi amaçlanmaktadır (7). Model ile kadının içinde bulunduğu değişim aşaması ve şiddeti durdurma yolunda geçmesi gereken değişim aşamaları belirlenmekte; bu aşamalara uygun müdahaleler seçilerek kadına yol gösterilmektedir (8). Bu modelde, kadını cesaretlendirmeye yönelik motivasyonel görüşmeler yapılmakta; değişimin kadının yaşantısında (kendisi, partneri, çocukları, sosyal çevresi vs.) yaratacağı olumlu ve olumsuz etkiler tartışılarak farkındalık yaratılmaktadır (9). Bu çalışmada aile içi şiddete maruz kalan S. olgusuna Değişim Modeli ile verilen eğitim/danışmanlık hizmetlerinin etkinliğinin değerlendirilmesi amaçlanmıştır.

\section{OLGU SUNUMU}

Veriler, sosyodemografik ve obstetrik öyküsünün de yer aldığ1 35 sorudan oluşan yarı-yapılandırılmış soru yönergesi kullanılarak derinlemesine görüşme yöntemi ile toplanmıştır.

Araştırmacılardan birisi ile komşuluk ilişkileri bulunan ve aile içi şiddete maruz kaldığı önceden bilinen S.'e Değişim Modeli uygulanmıştır. Bu kapsamda öncelikle S.'nin değişisimin hangi aşamasında olduğu (11) belirlenmiştir. Daha sonra S.'nin bir sonraki aşamaya ilerlemesi amacıyla; bulunduğu değişim aşamasına uygun olarak Değişim Modeli'nde tanımlanan bilişsel ve davranışsal süreçler doğrultusunda eğitim/danışmanlık verilmiştir.

Çalışmaya başlamadan önce S.’e çalışma hakkında bilgi verilmiş; çalışmaya katılımı ile ilgili sözel ve yazılı onamı alınmıştır. Bireyin mahremiyetini korumak için isim verilmeyip; kod adı olarak "S." kullanılmıştır. S.'den alınan bilgilerin sadece bilimsel amaçla kullanılacağı; başka bireyler ve kurumlar ile paylaşılmayacağ söylenerek; gizlilik ilkesine dikkat edilmiştir. Ayrıca S.'nin bilgilerinin alınmasının hem kadın hem de araştırmacı açısından ilerde sorunlar yaratabileceği öngörüldüğü için; S.’nin eşinin bu durumu öğrenmemesi için de bazı önlemler alınmıştır. Bu önlemler; kadına kod adı olarak S. harfi verilmiştir, hikâyesine bazı kurgulamalar eklenmiş ve hikayesi değiştirilmiştir. Yine S.'nin eşinin ve çocuğunun evde olmadığı saatler seçilerek, S. ile yalnız görüşme yapılmıştır.

\section{Değișim Modeli}

Model, Prochaska ve Diclemente tarafından 1982 yılında bireylerin hayatlarındaki sorunlu davranışları kabullenip, olumlu beklenti ve istek ile bu davranışı değiştirmelerine yol göstermek amacıyla geliştirilmiştir. Model, niyet öncesi, niyet, hazırlık (karar), eylem (hareket) ve sürdürme olmak üzere beş değişim aşamasından oluşmaktadır. Niyet öncesi basamakta bireyler problemin farkında değildir. Bu aşamadaki bireyler gelecek altı ay içinde davranış değişikliği için harekete geçme niyetinde değildirler. Modelin ikinci basamağı olan niyet basamağında bireyler problemin farkındadır ve muhtemel değişiklikleri düşünmektedir. Bu aşamada gelecek altı ay içinde değişim planlanmaktadır. Hazırlık (karar) aşamasında birey, gelecek ay eyleme geçmek için plan yapmaya başlamıştır. Prochaska ve Diclemente hazırlık aşamasını, eyleme geçişin ateşleyicisi olarak tanımlamaktadır. $\mathrm{Bu}$ aşamada birey bir eğitim sınıfına katılma, danışmalık alma, sağlık personeli ile konuşma ve kendisine yardımc1 olabilecek kitaplar alma gibi eylemlerde bulunabilir. Eylem (hareket) aşaması, son altı ay içinde bireylerin davranışında değişisimin olduğu aşamadır. $\mathrm{Bu}$ aşamada birey, davranışlarını, deneyimlerini veya çevrelerini değiştirmeyi dener. Son aşama olan sürdürme aşamasında ise birey, günlük aktivitelerinin bir parçası olarak yeni eylemlerini devam ettirir. Değişim, artık bir alışkanlığa dönüşmüştür. Ayrıca bu aşamada, önceki aşamalara geri dönüşlerin olma ihtimali daha azdır (6).

Değişim Modeli'ne göre bireylerin davranışlarını değiştirmek için rehberlik eden bilişsel ve davranışsal olmak üzere iki farklı süreç bulunmaktadır. Bilişsel süreçler; farkındalığın artması, dramatik rahatlama, evreyi yeniden değerlendirme, bireysel yeniden değerlendirme ve sosyal özgürleşmedir. "Farkındalığın artması" sürecinde amaç, bireye problem davranışın nedenleri, sonuçları ve çözümüne yönelik farkındalık kazandırmaktır. "Dramatik rahatlama" sürecinde problemli davranışın bireyde oluşturduğu olumsuz duyguların açığa çıkarılması ve bireye verdiği zararların ortaya konması amaçlanmaktadır. "Çevreyi yeniden değerlendirme" bir diğer bilişsel süreç olup; bu süreçte, olumsuz davranışın bireyin çevresindekileri (çocuğu, ebeveynler, arkadaşlar vs.) nasıl etkilediği ve bu etkilenmenin bireyde oluşturduğu duygular ortaya çıkarılmaya çalışılmaktadır. Bilişsel süreçlerden olan "bireysel yeniden değerlendirme" sürecinde bireyin davranış değişikliği yapmaya yönelik güçlü ve geliştirilmesi gereken yönlerini fark ettirmek amaçlanmaktadır. "Sosyal özgürleşme" ise son bilişsel süreç olup; bu süreçte, bireyin sorunlu davranıştan kurtulduğunda yaşaması muhtemel olumlu durumlar tartışılmaktadır. Davranışsal süreçler ise uyaran kontrolü, destekleyici ilişkiler, zıt koşullanma, ödüllendirme ve bireysel anlaşmadan oluşmaktadır. "Uyaran kontrolü" sürecinde, problemli davranışlara neden olan uyaranların ortadan kaldırılması amaçlanmaktadır. Davranışsal 
süreçlerden olan "destekleyici ilişkiler" sürecinde bireyin destek alabileceği bireyler, gruplar ve sistemler bulunmaya çalışılmaktadır. "Zit koşullanma" sürecinde ise, sağlıksız davranışların yerine konabilecek yeni bir sağlıklı davranış bulunmakta ve uygulamaya konmaktadır. Davranışsal süreçlerden olan "ödüllendirme" sürecinde bireyin sağlıksız davranışı ortadan kaldırmaya yönelik girişimlerine yönelik olumlu geri-bildirim verilmekte, birey ödüllendirilerek davranışı tekrar etmesi için cesaretlendirilmektedir. Son davranışsal süreç, "bireysel anlaşma" sürecidir. Bu süreçte bireyden yapmış olduğu değişikliği sürdüreceğine dair söz vermesi ve bu sözünü tutabilmesi için gerekli düzenlemelerin yapılması amaçlanmaktadır (6).

S. ile toplam 6 görüşme yapılmıştır. S.'nin evinde yapılan her bir görüşme, yaklaşık 1 saat sürmüştür. İlk dört görüşme bir hafta aralıklarla yapılmıştır. Beşinci görüşme, dördüncü görüşmeden bir ay sonra ve son görüşme ise beşinci görüşmeden altı ay sonra yapılmıştır. Uygulama toplam 10 ay sürmüştür. Görüşmeyi yapan araştırmac1, nitel görüşme deneyimine sahiptir ve araştırmacının ilgili modele yönelik çalışmaları bulunmaktadır.

\section{Görüşme}

İlk görüşmede S.'nin aile içi şiddet öyküsü alınmış; değişimin hangi aşamasında olduğu belirlenmiştir.

S., 33 yaşında, üniversite mezunu bir ev hanımıdır. Sekiz yıldır evli ve bir çocuk sahibi olan S., sosyoekonomik durumunu iyi olarak nitelendirmektedir. Görücü usulü ile evlenen S., eşi ile kuzendir. S.’nin eşi 34 yaşında, üniversite mezunu ve memurdur. Ailede gelirin harcanması konusundaki kararları daha çok S.'nin eşi vermektedir. Genel olarak evlilik memnuniyetini orta olarak değerlendiren S., yaklaşık dört yıldır eşi tarafından aile içi şiddete (fiziksel) maruz kaldığını belirtmektedir. S. şiddet gördüğü durumlarda evden ayrılarak ailesinin evine gittiğini, ancak şimdiye kadar şiddetten kurtulmak için herhangi bir yasal girişimde bulunmadığını; şiddet anında ise genellikle sustuğunu ve kendini koruyacak herhangi bir girişimde bulunmadığını ifade etmektedir. S. şiddet sonrası eşinin özür dilediğini, bir süre (yaklaşık bir ay) şiddet uygulamadığını, ancak daha sonra şiddet davranışının tekrarladığını belirtmektedir. S., şiddet görme gerekçesi olarak eşinin kıskançlığını, S.’nin ailesinin yakında oturmasını, aralarındaki uyum ve iletişim sorunlarını, eşinin eve ve çocuğa yeterince iyi bakmadığını düşünmesinden ve S.'nin ekonomik olarak bağımlı olmasından kaynaklandığını ifade etmektedir. Ayrıca S., eşi ile akrabalık durumunun aralarındaki sevgi bağının yeterli olmamasına neden olduğunu ve erken yaşta evlenmelerinin de şiddeti tetiklediğini düşündüğünü belirtmiştir. İlk görüşmede S.’nin niyet aşamasında olduğu saptanmıştır.

\section{Görüşme}

İlk görüşmeden bir hafta sonra yapılmıştır. Bu görüşmede S.'nin aile içi şiddete yönelik bilgi düzeyi ve şiddete yüklediği anlam belirlenmiştir. Daha sonra aile içi şiddete yönelik farkındalığının artması amacıyla hazırlanan eğitim (şiddetin tanımı, şiddetin önemi, şiddet türleri, şiddete uğradığı zaman başvuracağ1 kurumlar vb.) verilmiştir.

S., başlangıçta sadece fiziksel şiddete maruz kaldığını belirtirken görüşmelerde duygusal, sosyal ve ekonomik şiddete maruz kaldığını fark etmiştir.

Eğitim sonrası S. ile şiddetten kurtulmaya yönelik şimdiye kadar yaptığı girişimler, şiddetten kurtulmaya yönelik ümit/ümitsizlik duyguları tartışılarak; aile içi şiddetten kurtulan kadınların öykülerinden örnekler verilmiştir.

Görüşmede; dramatik rahatlama ve çevreyi yeniden değerlendirme süreçleri kullanılmıştır. $\mathrm{Bu}$ süreçlere yönelik S. ile aile içi şiddete maruz kalmanın kendisi, çocuğu, yakın çevresi ve yaşamı üzerindeki etkileri ve bu etkilerin onda oluşturduğu duygular tartışılmıştır.

S., şiddetin kendisinde korku, anksiyete, stres, baş etmede yetersizlik, güçsüzlük, yorgunluk, uykusuzluk, özgüven eksikliği, beden imajından memnuniyetsizlik; çocuğunda aşırı sevgi ve ilgi beklentisi, sinirlilik, uyumsuzluk, huzursuzluk; sosyal yaşantısında arkadaşlarıyla ve ailesiyle iletişim eksikliği, kararsızlık, izolasyon; ailesinde ise geleceğe yönelik endişe gibi olumsuz etkiler oluşturduğunun farkına varmıştır.

Görüşmenin sonunda bir sonraki görüşmeye getirmek üzere S.'den bir hafta boyunca şiddetten kurtulduğunda kendisi, ailesi ve çevresinin yaşamında ne tür değişiklikler olacağını zihninde canlandırması ve yazarak getirmesi istenmiştir. Bu ödev ile sosyal özgürleşme sürecini kullanmak amaçlanmıştır.

\section{Görüşme}

Üçüncü görüşme, ikinci görüşmeden bir hafta sonra yapılmıştır. Üçüncü görüşmeye S.'nin hazırladığı ödev tartışılarak başlanmıştır. Daha sonra uyaran kontrolünü sağlamak için; S.’e "Yanlış Düşünce Kalıpları", "Ben Dili” ve "Stres Yönetimi” eğitimi verilmiştir. Eğitim S. ile eşi arasında yaşanan iletişim çatışmalarını ele alacak şekilde interaktif olarak verilmiştir.

Eğitim sonrası S. ile şiddetle karşılaştığında kendisinin ve çocuğunun zarar görmesini önlemeye yönelik "güvenlik planı" yapılmıştır. Görüşmenin sonunda bir sonraki görüşmeye getirmek üzere S.'den şiddette "dur" diyebilmesi açısından bir kağıda güçlü ve güçlendirilmesi gereken yönlerini ve koşullarını yazması istenmiştir.

\section{Görüşme}

Dördüncü görüşme, üçüncü görüşmeden bir hafta sonra yapılmıştır. Bu görüşmede ilk olarak S.’e verilen ödev üzerinde tartışılmış; S.'nin güçlü ve geliştirilmesi gereken yönleri ve koşulları saptanmıştır.

Görüşmede bireysel yeniden değerlendirme süreci kullanılarak; şiddete "dur" demek için neler yapılabileceği üzerinde konuşulmuştur. Destekleyici ilişkileri belirlemek için S.'nin kullanabileceği destek sistemleri ortaya konmuştur. $\mathrm{Bu}$ görüşme sonunda $\mathrm{S}$., şiddete "dur" demeye hazır olduğunu belirtmiş; kendisi ve çocuğu için bunu yapacağına söz vermiştir. Böylece S. ile bireysel anlaşma sağlanmıştır. S.'e bundan sonraki görüşmelerin izlem ziyaretleri olacağı belirtilerek görüşme sonlandirılmıştır.

S., "ben dili”'ni günlük yaşamında kullanmaya başladığını belirtmiştir. Stres ile başa çıkmada etkili yollar geliştirdiği belirlenmiştir.

S., oluşturulan güvenlik planı kapsamında "acil çantası" hazırlayarak güvendiği bir komşusuna bırakmıştır. Acil durumlarda komşusunu haberdar etmek için telefonunda komşusunu "hızlı aramalar"a kaydetmiş ve aralarında üç kez çaldırdığında polisin aranması şifresini oluşturmuşlardır. Eşinin şiddet uygulayacağını fark 
ettiğinde güvenli bir ortama kaçabilmek için, kiler odasına anahtar yaptırmıştır.

Değişim aşamalarına yönelik uygulanan değişim süreçleri (bilişsel ve davranışsal süreçler) sonrasında yapılan dördüncü görüşmeden sonra S., hazırlı (karar) aşamasına geçmiştir

\section{Görüşme}

Beşinci görüşme, dördüncü görüşmeden bir ay sonra yapılmıştır. S.'nin şiddet görme durumu, güvenlik planının işlerliği, şiddete "dur" demeye yönelik planlanan girişimlerin uygulanıp uygulanmadığı, bu doğrultuda karşılaşılan engeller ve değişimin hangi aşamasında olduğu saptanmıştır. S. ile karşılaşılan engelleri aşmaya yönelik yeniden planlamalar yapılmıştır. Ayrıca S.'nin önceki aşamalara geri dönmesine neden olabilecek kırılma noktaları belirlenerek düzenlemeler yapılmıştır.

S. şiddete "dur" diyebilmek için para getiren bir işte çalışmaya başlamaya karar vermiştir. Yaşadıklarını ailesiyle (anne-baba, kız kardeş) paylaşmış ve gelecekte alacağı kararlar için yanında olmalarını istemiştir.

S.'e geldiği aşama açısından olumlu geri bildirim verilmiş; bu başarısından dolayı kendisini ve çocuğunu mutlu edecek bir aktivite planlanmıştır. Böylece S., değişim aşamasındaki ilerlemesinden dolayı ödüllendirilmiştir.

S., beşinci görüşmede eylem (hareket) aşamasına geçmiştir

\section{Görüşme}

Altınc1 görüşme, beşinci görüşmeden alt1 ay sonra yapılmıştır. $\mathrm{Bu}$ görüşmede, bir önceki görüşmede yapılanlar tekrar edilmiştir.

S. işe girebilmek için geçmesi gereken sınava yönelik kursa gitmeye karar vermiş, maddi ve ulaşım olanaklarına en uygun kursa gitmiş ve Kamu Personeli Seçme Sınavı'na girmiştir. Son görüşmede S.'nin sürdürme aşamasında olduğu saptanmıştır.

Görüşmeler sonunda elde edilen veriler Colaizzi içerik analizi yöntemi ile değerlendirilmiştir (11). Buna göre; bütün görüşmeler kaydedilmiştir ve yazıya dökülmüştür. Verilerin dökümü yapıldıktan sonra, veriler kodlanmıştır. Veri dökümü dört kez okunmuş ve notlar alınarak aynı ve farklı anlama gelen ifadeler kavramsallaştırılmıştır. Son olarak siniflandirılan ifadeler tema ve alt temalara ayrılmıştır (Tablo 1). Belirlenen temalar ve alt temalar doğrultusunda ise sonuçlar yorumlanmıştır.

Tablo 1. Temalar ve alt temalar

\begin{tabular}{|l|l|}
\hline Temalar & Alt Temalar \\
\hline Şiddet öyküsü & $\begin{array}{l}\text { Şiddetin nedenleri } \\
\text { Şiddete yönelik bilgi düzeyi } \\
\text { Şiddete yüklediği anlam }\end{array}$ \\
\hline $\begin{array}{l}\text { Şiddetten kurtulmaya } \\
\text { yönelik girişimler }\end{array}$ & $\begin{array}{l}\text { Destek sistemleri } \\
\text { Güvenlik planı } \\
\text { Stres ile başa çıkma yöntemleri }\end{array}$ \\
\hline Şiddetin etkileri & $\begin{array}{l}\text { Şiddetin kendisi üzerindeki etkisi } \\
\text { Şiddetin çocuğu üzerindeki etkisi } \\
\text { Şiddetin yakın çevresi üzerindeki } \\
\text { etkisi }\end{array}$ \\
\hline $\begin{array}{l}\text { Şiddetten kurtulmaya } \\
\text { yönelik duygu ve } \\
\text { düşünceler }\end{array}$ & $\begin{array}{l}\text { Şiddete "dur" diyebilmesinde } \\
\text { güçlü yönleri } \\
\text { Şiddete "dur" diyebilmesinde } \\
\text { güçlendirilmesi gereken yönleri }\end{array}$ \\
\hline
\end{tabular}

\section{TARTIŞMA}

Aile içi şiddet, günümüzde devam eden evrensel bir sorundur. Literatürde aile içi şiddetin prevalansını, etkilerini ve etkileyen faktörlerini ortaya koyan birçok çalışma olmasına rağmen; şiddetin durdurulmasına ya da çözümüne yönelik girişimsel çalışmalar sınırlı sayıdadır (12-14). Ulusal ve uluslararası anlamda kadını şiddetten korumaya yönelik yasalar (Kadınlara Karşı Her Türlü Ayrımcılığın Önlenmesi Sözleşmesi-CEDAW, Kadına Yönelik Şiddetin Ortadan Kaldırılması Bildirgesi, Pekin Deklarasyonu ve Eylem Platformu, 2030 Sürdürülebilir Kalkınma Hedefleri, 6284 sayılı Ailenin Korunması ve Kadına Karşı Şiddetin Önlenmesine Dair Kanun, İstanbul Sözleşmesi, Ailenin Korunmasına Dair Kanun, Çocuk ve Kadına Yönelik Şiddet Hareketleri ile Töre ve Namus Cinayetlerinin Önlenmesi için Alınacak Tedbirler, Kadına Yönelik Aile İçi Şiddetle Mücadele Ulusal Eylem Planı 2007-2010, 2012-2015, 2016-2020, Kadına Yönelik Aile İçi Şiddetin Önlenmesi Projesi, Mesleki Becerilerin Geliştirilmesi Projesi vs.) ve düzenlemeler (Aile ve Sosyal Politikalar Bakanlığı İl Müdürlükleri ve Sosyal Hizmet Merkezleri, Şiddet Önleme ve İzleme MerkezleriŞÖNIM, Kadın Konukevleri, ALO 183 Sosyal Destek Hattı, Kadın Danışma/Dayanışma Merkezleri, Eğitim Programlar1, vs.) olsa da; uygulamada yetersiz kalmaktadır. Aile içi şiddet hala dünyada $\% 35$; Türkiye'de ise \%36 (fiziksel) ve \%44 (duygusal) gibi çok yüksek oranlarda görülen ve kadın sağlığını etkileyen bir sorun olarak devam etmektedir $(15,16)$.

Kadınlar, özellikle toplumsal cinsiyet eşitsizliğinin var olduğu ülkelerde, gerek güçsüz oldukları (çalışmıyor olma, eğitim seviyesinin düşük olması, zarar görme/ölüm korkusu, çocukların bakımına yetememe kaygısı, ekonomik yetersizlik, özgüven yetersizliği vb.), gerekse toplumsal baskı (boşanmış kadın imajı, ailenin onay vermemesi vb.) nedeniyle şiddet uygulayan eşten uzaklaşmayı göze alamamakta ve aile içi şiddetten kurtulması mümkün olmamaktadır. $\mathrm{Bu}$ nedenle şiddete maruz kalan kadınların eşinden ayrılmadan şiddeti durduracak düzeyde güçlü konuma getirilmesini sağlayan girişimlere ihtiyaç duyulmaktadır.

Aile içi şiddete maruz kalan kadınları güçlendirmek amacıyla kullanılan araçlardan birisi Değişim Modelidir. Değişim Modeli, kadını güçlendirerek ve kadının potansiyelini kullanarak kendisini aile içi şiddetten korumasında ve şiddeti durdurmasında kullanılabilecek uygun bir yaklaşım olarak önerilmiştir (9,17-20). Buradan yola çıkarak yaptığımız çalışmamızda S., değişimin niyet aşamasından sürdürme aşamasına (10 ayda) geçmiştir.

Literatürde aile içi şiddete uğrayan kadınlarda Değişim Modeli kullanılarak yapılan çalışmalarda farklı sonuçlar olduğu görülmüştür. Aile içi şiddete uğrayan kadınlara (23 kadın) yönelik Değişim Modeli'nin kullanıldığı Amerika Birleşik Devletleri'nde yapılan bir çalışmada; kadınların bilişsel ve davranışsal süreçleri kullanarak şiddet deneyimlerini anlama/anlamlandırma ve şiddeti sonlandırmada bu modeli etkin olarak kullandıkları bildirilmiştir (9). Bu çalışmadan sonra aynı ekip tarafından daha büyük örneklemde (96 kadın) çalışma tekrarlanmış ve modelin şiddeti durdurmaya yönelik müdahale ve girişimleri ortaya koyması bakımından önemli olduğu belirtilmiştir (21). Amerika Birleşik 
Devletleri'nde yapılan başka bir çalışmada ise kullanılan Değişim Modeli ile (32 kadın) kadınların eşlerinin şiddet davranışlarını değiştiremeseler de şiddete verdikleri tepkiler üzerinde kontrol sahibi oldukları bildirilmiştir. Çalışmada ayrıca Değişim modeli'nin kullanılmasının, hem sağlık personeli hem de kadın için değişim süreçlerini hızlandırdığı öne sürülmüştür (22). Değişim Modeli'ni kullandığımız çalışmamızda model aile içi şiddeti durdurmada etkili bulunmuş ve literatürle uyum göstermiştir.

Değişim Modeli'nin aile içi şiddette kullanıldığı ve olumlu sonuçlar alındığı çalışmalar bulunmakla birlikte bazı çalışmalarda sürdürme aşamasında değişimin ilk aşamalarına gerilemeler olduğu bildirilmiştir. Kanada'da 19 kadınla Değişim Modeli'nin kullanıldığı bir çalışmada kadınların niyet öncesi aşamadan sürdürme aşamasına geçmelerinin yaklaşık 12 ay sürdüğü ve sürdürme aşamasında "geri dönüş noktalarının" olduğu belirtilmiştir. Araştırmacılar, geri dönüşleri kadınların sosyal yaşama yönelik algıladıkları risklerin oluşturduğunu saptamışlardır (19). Benzer şekilde yapılan iki ayrı çalışmada da kadınların değişim aşamalarını etkili olarak geçtikleri ancak geri dönüşler yaşandığ 1 belirtilmiştir $(18,20)$. $\mathrm{Bu}$ nedenle Değişim Modeli kullanımında sürdürme aşamasında kadınların izlemlerinin devam ettirilmesi, geri dönüş noktalarının belirlenerek, bunlara yönelik önlemler alınması gerekmektedir.

\section{SONUC VE ÖNERILER}

Model uygulanmadan önce değişim basamaklarından niyet aşamasında olan S., model kullanımı sonrasında sürdürme aşamasına geçmiştir. Aile içi şiddete uğrayan kadınlarda Değişim Modeli'nin kullanılmasının, kadının güçlendirilerek şiddeti durdurmasında uygun süreçlerin planlanması, müdahalelerin uygulanması ve değerlendirmesinde etkili olacağı düşünülmektedir. Literatürde sınırlı sayıda yapılan çalışma sonuçlarından yola çıkarak modelin etkinliğinin daha farklı gruplarla uygulanmasına gereksinim olduğu düşünülmekte ve bu doğrultuda daha fazla çalışmaların yapılması önerilmektedir.

\section{KAYNAKLAR}

1. Pehlivan M. Aile içi şiddette kadının mağduriyeti (Sakarya Sögütlü örneği). The Journal of Academic Social Science Studies. 2017; 58: 551-69. doi: 10.9761/JASSS7146.

2. Jahromi MK, Jamali S, Koshkaki AR, Javadpour S. Prevalence and risk factors of domestic violence against women by their husbands in Iran. Global Journal of Health Science. 2016; 8(5): 175-83.

3. Kalra N, Di Tanna GL, García-Moreno C. Training healthcare providers to respond to intimate partner violence against women. Cochrane Database Syst Rev. 2017; (2): CD012423.

4. Yaman Ş, Taşkın L. Emergency nurses barriers to intervention of domestic violence in Turkey: A qualitative study. Sexuality and Disability. 2012; 30(4): 441-51.

5. Knox B. Screening women for intimate partner violence: Creating proper practice habits. The Nurse Practitioner. 2018; 43(5): 14-20.
6. Prochaska JO, Diclemente CC. Transtheoretical Therapy: Toward a more integrative model of change. Psychotherapy Theory Research \& Practice. 1982; 19(3): 276-88.

7. Reisenhofer S, Taft A. Women's journey to safetyThe Transtheoretical Model in clinical practice when working with women experiencing intimate partner violence: A scientific review and clinical guidance. Patient Education and Counseling. 2013; 93(3): 53648.

8. Yaman Ş. Aile içi şiddete uğrayan kadınlara yönelik hemşirelik hizmetlerinde "Değişim Modelinin" kullanılması. Maltepe Üniversitesi Hemşirelik Bilim ve Sanat1 Dergisi. 2009; 2(3): 130-5.

9. Burke JG, Denison JA, Gielen AC, McDonnell KA, O’Campo P. Ending intimate partner violence: An application of the Transtheoretical Model. American Journal of Health Behavior. 2004; 28(2): 122-33.

10. Fraiser PY, Slatt L, Kowlowitz V, Glowa PT. Using the stages of change model to counsel victims of intimate partner violence. Patient Education and Counselling. 2001; 43(2): 211-7.

11. Colaizzi PP. Psychological research as a phenomenologist views it. In: Valle RS, King M, editors. Existential-Phenomenological alternatives for Psychology. New York: Oxford University Press; 1978. p. 49-59.

12. Michau L, Horn J, Bank A, Dutt M, Zimmerman C. Prevention of violence against women and girls: Lessons from practice. The Lancet. 2015; 385(9978): 1672-84.

13. Pronyk PM, Hargreaves JR, Kim JC, Morison LA, Phetla G, Watts C, et al. Effect of a structural intervention for the prevention of intimate-partner violence and HIV in rural South Africa: A cluster randomised trial. Lancet. 2006; 368(9551): 1973-83.

14. Kim JC, Watts CH, Hargreaves JR, Ndhlovu LX, Phetla G, Morison LA, et al. Understanding the impact of a microfinance-based intervention on women's empowerment and the reduction of intimate partner violence in South Africa. American Journal of Public Health. 2007; 97(10):1794-802.

15. who.int [Internet]. World Health Organization (WHO). Global and regional estimates of violence against women: Prevalence and health effects of intimate partner violence and non-partner sexual violence [Update: 2013; Cited: 03.09.2018]. Available from: http://www.who.int/violence_injury _prevention/ violence/sexual/en/.

16. T.C. Aile ve Sosyal Politikalar Bakanlığı. Hacettepe Üniversitesi Nüfus Etütleri Enstitüsü. Türkiye'de Kadına Yönelik Aile İçi Şiddet Araştırması. Ankara: Elma Yayınc1lık; 2015.

17. Haggerty LA, Goodman LA. Stages of change-based nursing interventions for victims of interpersonal violence. Journal of Obstetric, Gynecologic, Neonatal Nursing. 2003; 32(1): 68-75.

18. Chang JC, Dado D, Ashton S, Hawker L, Cluss PA, Buranosky R, et al. Understanding behavior change for women experiencing intimate partner violence: Mapping the ups and downs using the stages of change. Patient Education and Counseling. 2006; 62(3): 330-9. 
19. Catallo C, Jack SM, Ciliska D, MacMillan HL. Identifying the turning point: Using the transtheoretical model of change to map intimate partner violence disclosure in emergency department settings. ISRN Nursing. 2012; 2012. Article ID 239468. doi:10.5402/2012/239468.

20. Schrager JD, Smith LS, Heron SL, Houry D. Does stage of change predict improved intimate partner violence outcomes following an emergency department intervention? Academic Emergency Medicine. 2013; 20(2): 169-77. doi: 10.1111/acem.12081.

21. Burke JG, Mahoney P, Gielen A, McDonnell KA, O'campo P. Defining appropriate stages of change for intimate partner violence survivors. Motivational Interviewing and Stages of Change in Intimate Partner Violence. 2009; 24(1): 273-303.

22. Zink T, Elder N, Jacobson J, Klostermann B. Medical management of intimate partner violence considering the stages of change: Precontemplation and contemplation. The Annals of Family Medicine. 2004; 2(3): 231-9. doi: 10.1370/afm.74. 